\title{
RELACIONAMENTOS DE COOPERAÇÃO ENTRE EMPRESAS DE MICRO E PEQUENO PORTE: UM ESTUDO DOS FOOD TRUCKS DO DISTRITO FEDERAL
}

\section{COOPERATION RELATIONSHIPS AMONG MICRO AND SMALL BUSINESSES: A STUDY OF FOOD TRUCKS IN THE FEDERAL DISTRICT}

\author{
Amanda Reis de Almeida Apolinário \\ Universidade de Brasília - Brasília - DF \\ amanda_reis03@hotmail.com \\ Helena Araújo Costa \\ Universidade de Brasília - Brasília - DF \\ helenacostaunb@gmail.com \\ Newton da Silva Miranda Júnior \\ Universidade de Brasília - Brasília - DF \\ newtondasmir@gmail.com
}

\begin{abstract}
Resumo
Os food trucks, entendidos como empreendimentos itinerantes do ramo de alimentos, foram tratados como foco desta pesquisa tanto por serem uma atividade recente quanto por serem caracterizados como micro e pequenas empresas (MPE). Assim como outras empresas, os food trucks podem vislumbrar a cooperação entre eles como uma fonte de vantagem competitiva. O presente estudo buscou investigar os relacionamentos de cooperação entre food trucks do Distrito Federal e os benefícios proporcionados pelas ações conjuntas entre eles. Realizou-se uma pesquisa descritiva de abordagem quantitativa. A coleta de dados deu-se por meio de questionário estruturado e uma amostragem por conveniência de 31 estabelecimentos. Entre os respondentes, predominaram microempresas, com o tempo de atuação entre 7 a 12 meses e com faturamento acima de 10 mil reais/mês. Quanto aos relacionamentos de cooperação entre os trucks, percebeu-se a existência mais de parcerias, embora informais, do que desentendimentos. As ações de cooperação realizadas são simples: indicações de outros trucks para clientes e a divulgação dos eventos em redes sociais. As evidências sugerem que vantagens reconhecidas pela maioria dos gestores dizem respeito à ampliação da força política desses empreendimentos; aumento de conhecimentos para o negócio; maior divulgação, clientela e desempenho financeiro; e inovações do processo/produto.
\end{abstract}

Palavras-chaves: Relacionamento de Cooperação. Empresas de Pequeno Porte. Foods Trucks. Distrito Federal.

\begin{abstract}
Food trucks, understood as itinerant food business enterprises, were treated as the focus of this research because in addition to being a recent activity, they are also micro and small enterprises (SME). Like other companies, food trucks can visualize cooperation between them as a source of competitive advantage. The
\end{abstract}


present study sought to investigate the relationships of cooperation between food trucks of the Distrito Federal and the benefits provided by the joint actions between them. A descriptive quantitative approach was carried out. The data collection was done through a structured questionnaire and a convenience sample of 31 establishments. The presence of microenterprises was quite frequent, with the time of operation between 7 and 12 months and with revenues above 10 thousand reais / month. As for the relationships of cooperation between the trucks, it was perceived that there are more partnerships, albeit informal ones, than misunderstandings. The cooperation actions carried out are simple: indications of other trucks for clients and the dissemination of events in social networks. Evidence suggests that advantages recognized by most managers relate to the expansion of the political strength of these ventures; increase knowledge for the business; greater disclosure, clientele and financial performance; and process / product innovations.

Keywords: Cooperation Relationship. Small Businesses. Foods Trucks. Distrito Federal.

\section{Introdução}

A cooperação entre empresas pode despontar como uma alternativa para contornar entraves (GEROLAMO et al., 2008; OLAVE; NETO, 2001). Estes relacionamentos cooperativos podem ser entendidos como práticas ou ações realizadas conjuntamente por empresas congêneres que competem entre si no mercado (CASAROTTO; PIRES, 2001). Dessa cooperação, podem emergir vantagens para as empresas parceiras, especialmente aquelas de pequeno porte: criação de novos mercados; desenvolvimento de pesquisas e novos produtos; melhor gestão da informação e de tecnologias; união para a defesa de interesses; ações de marketing coletivo (BALESTRIN; VARGAS, 2004; OLAVE; NETO, 2001).

Um exemplo dessas empresas de micro e pequeno porte (MPE) são os food trucks, pequenos caminhões ou trailers que vendem produtos alimentícios de maneira itinerante. Essas empresas se valem de sua mobilidade para prover a variedade buscada por seu público e o crescimento da oferta desse setor está associado à proliferação da tecnologia (ANENBERG; KUNGB, 2015). Tal segmento empresarial pode ser considerado como uma transformação no setor alimentício (SCHIFELING; DEMETRY, 2014). Eles são vistos como novidades (HOFFMANN et al., 2016) que contribuem à inovação, tanto pela gastronomia quanto pela lógica operacional (PERINI; GUIVANT, 2017), do conceito de comércio itinerante de comida de rua (SOUZA; LOPES, 2017).

Os food trucks apresentam um novo modelo de negócio de baixos custos demandados e com uma potencial clientela, de forma com que consigam muitas vezes alcançar o sucesso (SEBRAE, 2017). Seu modelo apresenta uma forma diferenciada, buscando suprir as necessidades de seus clientes, que buscam praticidade, qualidade e modernidade (SILVA; LIMA; LOURENÇO, 2015).

Os food trucks tendem a terem portes bastante reduzidos, e como outras MPE, podem estabelecer relações de cooperação. $O$ aspecto da distribuição espacial destes empreendimentos já foi abordado por Schifeling e Demetry (2014), todavia sem tratar dos relacionamentos entre eles. Assim, por serem pequenas e terem uma capacidade de atração limitada (VERSHOORE; BALESTRIN, 2010), além de outros limitadores, esses empreendimentos tem mostrado uma tendência a se concentrarem em certos locais, seguindo uma agenda organizada, passando a ocupar espaços urbanos e a terem maior visibilidade em Brasília desde 2015. Esse comportamento despertou os pesquisadores para conhecerem e explorarem a dinâmica de relacionamentos estratégicos que poderia estar sendo configurada entre estas pequenas empresas com características peculiares, tais como sua mobilidade.

Assim, a abordagem aqui proposta, baseada em um survey com gestores deste segmento, tem como objetivo investigar os relacionamentos de cooperação entre food trucks do Distrito Federal e os benefícios proporcionados pelas ações conjuntas entre eles. Esta pesquisa enriquece a visão sobre tais modelos de negócios ao complementar outros recentes trabalhos que abordaram os food trucks sob o ponto de vista de suas vantagens competitivas (HOFFMANN et al., 2016), de seus consumidores (SILVA; LIMA; LOURENÇO, 2015; SOUZA; LOPES, 2017) e sob a regulação estatal nesse tipo de comércio (WILLIAMS, 2013). 


\section{RELACIONAMENTOS DE COOPERAÇÃO ENTRE EMPRESAS DE MICRO E PEQUENO PORTE: UM ESTUDO DOS FOOD TRUCKS DO DISTRITO FEDERAL}

O artigo inicia-se pela fundamentação teórica, a qual está assentada na interconexão entre a teoria organizacional da visão baseada em recursos e estudos empíricos voltados à cooperação entre MPEs. Na seção metodológica, apresentam-se os procedimentos e o tipo de análise de dados adotados. Por fim, são apresentados os resultados alcançados e a discussão em torno deles, assim como as considerações finais.

\section{Fundamentação Teórica}

\section{Visão baseada em recursos e cooperação entre micro e pequenas empresas}

A cooperação entre MPEs é apontada recorrentemente como fonte de vantagem competitiva (GEROLAMO et al., 2008; MAGALHÃES; DAUDT; PHONLOR, 2009; OLAVE; NETO, 2001). Tal fenômeno é abordado na literatura sob variadas perspectivas teóricas. Entre elas, ressalta-se a visão baseada em recursos (BARNEY, 1991), a exemplo do estudo de Eisenhardt e Schoonhoven (1996). Tais autores enfatizam a perspectiva teórica da visão baseada em recursos para explicar a formação de alianças estratégicas. Argumentam que as alianças estratégicas tendem a ser formadas quando as firmas se encontram em posição de vulnerabilidade estratégica, quer seja porque estão inseridas em cenários emergentes ou alta competitividade, quer seja porque estão desbravando o pioneirismo em técnicas estratégicas (EISENHARDT; SCHOONHOVEN, 1996).

Verschoore e Balestrin (2008) encontraram indícios de que redes de cooperação podem ser formadas também como mecanismo de acesso a soluções, obtenção de aprendizagem e inovação, melhores relações sociais e redução de custos e riscos. Outros benefícios advindos da cooperação são: força política maior, know how acerca do negócio empreendido, avanços de marketing, assim como inovações em processos e produtos (GEROLAMO et al., 2008; MAGALHÃES; DAUDT; PHONLOR, 2009; OLAVE; NETO, 2001).

As MPEs precisam recorrer a alternativas para fazer frente ao aumento da competição (MAGALHÃES; DAUDT; PHONLOR, 2009). Uma delas são as parcerias interorganizacionais que podem conduzir a uma sinergia de complementaridade de recursos além de proporcionar diferenciação e otimização no uso deles (OLAVE; NETO, 2001). Alguns exemplos dessas parcerias incluem participação em cursos, treinamentos ou palestras de capacitação da mão de obra, compras de matéria-prima em conjunto, compartilhamento de informações do mercado entre as empresas, investimentos para desenvolvimento do setor, marketing em conjunto, participação em eventos, contratação de consultorias para aperfeiçoamento das áreas mais críticas de gestão e discussões e estudos em grupo para implementações de melhoria na cadeia produtiva (CASTRO; BULGACOV; HOFFMANN, 2011).

Sob a perspectiva da visão baseada em recursos, a ação coletiva entre empresas de pequeno porte pode conduzir a recursos inimitáveis, a exemplo de estruturas colaborativas e formas alternativas de relacionamento (BALESTRIN; VERSCHOORE; PERUCIA, 2014). As parcerias entre empresas podem ser vistas como oportunidades para o ganho de novos recursos e competências, sendo que as alianças estratégicas tendem a crescer quando firmas vislumbram nelas a oportunidade de acessar recursos indisponíveis até então (EISENHARDT; SCHOONHOVEN, 1996).

As benesses geradas coletivamente podem igualmente sustentar uma estratégia para competir no mercado (BALESTRIN; VERSCHOORE; PERUCIA, 2014). Segundo esses autores, essa constatação de visão relacional da estratégia, complementa os pressupostos teóricos da visão baseada em recursos. A concepção de distribuição não homogênea de recursos entre as firmas representa o cerne conceitual da teoria da visão baseada em recursos (HEINE; RINDFLEISCH, 2013). Essa teoria concebe a vantagem competitiva como um reflexo desses recursos e capacidades historicamente idiossincráticos à firma (BARNEY, 1991).

\section{Food Trucks como MPEs e suas principais características}

Os food trucks têm se tornado um segmento popular no ramo alimentício e também de sucesso financeiro, sendo denominados de nova tendência de comida móvel (WILLIAMS, 2013). Estudando o contexto norte- 
americano, Williams (2013) assevera que historicamente a venda ambulante, considerada como um elemento da vida urbana, caracterizou-se como uma fonte de oportunidade econômica a empresas de pequeno porte que, em geral, pertenciam a imigrantes e pessoas de rendas menores. Os food trucks se diferem do tradicional comércio ambulante de rua e vem ganhando espaço na sociedade em paralelo com as mudanças na forma de se alimentar vivenciadas pela sociedade devido à modernidade urbana (SILVA; LIMA; LOURENÇO, 2015).

O sucesso alcançado por esse tipo de comércio itinerante ao ar livre no que se refere à atração de público pode ser atribuído, sobremaneira, aos aspectos de informalidade, descontração, praticidade, rapidez e preços acessíveis proporcionados (PERINI; GUIVANT, 2017). Quanto ao público consumidor, Perini e Guivant (2017) refutam os estudos que concebem os food trucks como empreendimentos frequentados apenas por classes de maior poder aquisitivo e culturalmente diferenciada.

Embora bastante atrelados à empresas de pequeno porte ou a empreendedores, os food trucks também despontam como uma alternativa a restaurantes já estabelecidos no mercado quanto a novas oportunidades de atuação no mercado alimentício (WILLIAMS, 2013). Por food truck, entende-se uma cozinha comercial móvel em miniatura que atua sobre rodas transportando e vendendo alimentos ao público, de forma itinerante, sendo a maioria dos veículos trailers, furgões, camionetes ou caminhões adaptados (WILLIAMS, 2013). $O$ valor do investimento pode ser bem variado, dependendo da tecnologia utilizada pela empresa e a necessidade de adaptação dos equipamentos a serem instalados (SEBRAE, 2017). Outro fator essencial para entrarem em funcionamento é obter a concessão da administração da cidade e da vigilância sanitária (LUDWIG; NETO, 2017; WILLIAMS, 2013).

O crescimento do setor de food trucks pode ser atrelado a diversas variáveis, envolvendo desde a popularização desse tipo de comércio itinerante por meio de programas televisivos voltados à culinária até o fetichismo envolto nos alimentos (PERINI; GUIVANT, 2017; WILLIAMS, 2013). A popularização pode ser atrelada ao aumento do interesse por gastronomia, à popularização dos chefs como celebridades, ao aumento das refeições fora do lar e à cultura foodie (PERINI; GUIVANT, 2017). Sob a perspectiva empresarial, a rentabilidade dos food trucks pode ser associada aos menores custos iniciais demandados, se comparados àqueles de restaurantes, e à capacidade de preparar alimentos com mobilidade (WILLIAMS, 2013), alcançando um público mais variado.

Hoffmann et al. (2016), a partir da visão baseada em recursos, buscaram identificar as fontes de vantagem competitiva sustentável aos food trucks de Brasília - DF que possibilitaram a esses empreendimentos um desempenho acima da média. Esses autores constataram uma variedade de recursos potenciais à promoção de vantagens competitivas sustentáveis, tais como: o modelo do truck, a exclusividade da matériaprima, a geração de energia, os equipamentos, a network, o conhecimento técnico dos funcionários, o bom atendimento, a obtenção de receita própria, a reputação da empresa e investimentos e o bom atendimento.

A partir da perspectiva do marketing de relacionamento, Souza e Lopes (2017) identificaram os atributos de negócio, subdivididos em variáveis de gestão e formato de negócio, que mais influenciaram na intenção de recomendação e reuso dos serviços prestados pelos food trucks, segundo os próprios consumidores. Entre as variáveis de gestão do negócio, o sabor da comida e a limpeza percebida do local foram os fatores mais influenciadores da intenção de recomendação. Por outro lado, a apresentação do food truck e o custo/benefício foram os fatores mais influentes na intenção de reuso.

Silva et al. (2015) buscaram investigar a influência do comportamento do consumidor no modelo de negócio dos food trucks. Segundo esses autores, os aspectos socioculturais dos consumidores da sociedade atual podem influenciar na longevidade, além de direcionar e determinar os rumos desse tipo de comércio itinerante de trucks. Sob a perspectiva da regulação estatal, Williams (2013) salientam que ao Estado cabe regular o comércio itinerante de food trucks sem, contudo, criar entraves a esse segmento. Trata-se de uma indústria capaz de proporcionar oportunidades a empreendedores, assim como chances de crescimento a restaurantes já estabelecidos (WILLIAMS, 2013). 


\section{RELACIONAMENTOS DE COOPERAÇÃO ENTRE EMPRESAS DE MICRO E PEQUENO PORTE: UM ESTUDO DOS FOOD TRUCKS DO DISTRITO FEDERAL}

Especificamente no que diz respeito à cooperação entre o comércio itinerante representado pelos food trucks que, até então, está inexplorado na literatura, conforme varredura realizada nas principais bases de dados nacionais. Vislumbra-se que isso se dá pelo fato de que, apesar de a cooperação já ser um tema vastamente estudado, o modelo de negócios dado pelos food trucks é uma nova tendência (HOFFMANN et al., 2016). Esta é uma das lacunas que este estudo pretende colaborar a suprir.

\section{Metodologia}

O presente estudo caracteriza-se como descritivo com enfoque quantitativo. A falta de dados oficiais sobre a quantidade de food trucks existentes no Distrito Federal e também por fatores internos da pesquisa, como o tempo previsto para coleta e análise de dados, levou à adoção de uma amostragem não probabilística por conveniência. $O$ critério de seleção de trucks para responderem o questionário foi a quantidade de participação em no mínimo três eventos voltados a esse tipo de comércio itinerante em espaços públicos nas localidades: Asa Sul, Asa Norte, Lago Sul, Park Sul, Águas Claras, Vicente Pires e Ceilândia.

Quanto aos procedimentos e técnicas de pesquisa, empregou-se o questionário como instrumento de coleta de dados. A construção do questionário teve como base a literatura consultada e o instrumento de pesquisa de Miranda Júnior (2013). Por sua vez, o questionário foi composto por 4 blocos que organizavam 31 questões fechadas. As variáveis utilizadas em cada bloco estão descritas no Quadro 1.

\begin{tabular}{|l|l|}
\hline Blocos & Variáveis \\
\hline 1 - Caracterização dos food trucks & $\begin{array}{l}\text { Principal produto; Tempo de atividade; CNPJ; Número de funcionários; } \\
\text { Faturamento médio mensal }\end{array}$ \\
\hline 2 - Cooperação: visão geral & Relacionamento de cooperação; Contratos formais; Oportunismo; Confiança \\
\hline 3 - Cooperação: ações & $\begin{array}{l}\text { Indicar trucks para eventos ou clientes; Investimentos em infraestrutura; } \\
\text { Realização de treinamentos e consultorias; Compras em conjunto. }\end{array}$ \\
\hline 4 - Vantagens observadas & $\begin{array}{l}\text { Crédito bancário; Desempenho financeiro; Clientes; Divulgação; Força política; } \\
\text { Conhecimentos; Inovação. }\end{array}$ \\
\hline
\end{tabular}

Quadro 1: Estruturação do questionário

Fonte: elaboração própria

A aplicação do questionário foi realizada junto aos proprietários e/ou gerentes dos food trucks abordados, totalizando-se em 31 respondentes. Primeiramente aplicou-se o pré-teste, e em seguida o questionário. 0 pré-teste foi aplicado em dois food trucks com as mesmas características dos outros respondentes. Em seguida, a coleta de dados que ocorreu durante 3 semanas entre os meses de dezembro e janeiro

\section{Resultados e Análises}

\section{Caracterização dos food trucks respondentes}

O modelo de negócio de food trucks é um segmento em ascensão do ramo gastronômico do país e, inclusive, no Distrito Federal (Hoffmann et al., 2016). Segundo esses autores, trata-se de um modismo percebido ao longo dos anos no Distrito Federal, sobremodo a partir de 2014. Os dados relativos ao tempo de atuação dos food trucks abordados nessa pesquisa corroboram essa expansão em anos mais recentes, sendo 0 empreendimento mais antigo, entre os abordados, atuante há 18 meses. Para representar o tempo de atuação dos empreendimentos de food trucks do presente estudo, foram criadas três categorias: recém entrantes, correspondendo ao tempo de atuação entre 1 a 6 meses, intermediários, com atuação entre 7 a 12 meses e veteranos, atuantes de 13 a 18 meses. Em termos percentuais, os food trucks com tempo de atuação intermediário predominaram sobre os demais (57\%), seguidos pelos recém-entrantes $(27 \%)$ e, por fim, os veteranos $(17 \%)$. 
A ascensão desse segmento gastronômico pode estar relacionada aos indícios de retornos financeiros vantajosos e consideráveis níveis de faturamento obtidos por esse modelo de negócio (Marques et al., 2016). Entre os food trucks abordados nesse estudo, 35\% declararam faturar até $\mathrm{R} \$ 10 \mathrm{mil} / \mathrm{mês,} \mathrm{sendo} \mathrm{que}$ os demais $65 \%$ declararam faturamento acima desse valor. Cabe salientar que, afora os dados obtidos nessa pesquisa por meio dos questionários, alguns respondentes assumiram preencher faturamento aquém daquele realmente alcançado em seus food trucks, deixando-se a pressupor que o faturamento como um todo pode ser maior do que o aqui constatado.

Em relação à quantidade de funcionários atuantes nos food trucks, a maior quantidade registrada foi 11, havendo uma grande concentração de empreendimentos que declararam possuir de 2 a 4 funcionários (77\%). Pode-se dizer, com base na metodologia de apuração do porte de empresas por meio da quantidade de empregados do Sebrae (2017), que todos os food trucks abordados na pesquisa se enquadram como microempresas.

Os itens ofertados pelos food trucks englobaram expressiva variedade de gêneros alimentícios, além de bebidas e gelados. A oferta compreendeu alimentos tradicionalmente considerados fast food (hambúrguer, sanduíche, cachorro-quente); alimentos regionais brasileiros ou estrangeiros (tapioca, arroz carreteiro, yakissoba, parrilha, kebab, calzone, sushi, temaki); bebidas (cervejas, refrigerantes, água) e gelados (paletas, picolés, açaí). Entre os 31 participantes da pesquisa, foram registrados 16 diferentes produtos. Em relação às categorias criadas para representar tais itens, com base em Hoffmann et al. (2016a), a oferta de refeições $(74 \%)$ prevaleceu sobre as demais: gelados (13\%), bebidas $(6 \%)$ e outros $(6 \%)$. Especificamente em relação aos itens, a quantidade de food trucks destinados a hambúguer/sanduíche foi a mais recorrente $(26 \%)$, seguido por aqueles do ramo de paletas mexicanas ou picolés artesanais (10\%) e cachorro-quente $(10 \%)$.

Em resumo, pode-se afirmar que os food trucks participantes da pesquisa podem ser caracterizados como microempresas, com tempo de atuação predominante de 7 a 12 meses, que tende a faturar, em sua maioria, valores superiores a $\mathrm{R} \$ 10.000$ mensais, e que tem sua oferta concentrada em refeições rápidas, especialmente sanduíches, ainda que tenham sido identificados 16 diferentes produtos.

\section{Os Relacionamentos de Cooperação entre os food trucks}

Nessa seção, buscou-se caracterizar como se dão os relacionamentos cooperativos entre os food trucks. De modo geral, para expressiva maioria dos respondentes (87\%), é possível se afirmar que existem relacionamentos de cooperação nesse segmento de mercado da cidade. Ainda, o ambiente de relacionamentos entre os food trucks é visto, pela maioria dos respondentes $(65 \%)$, como um espaço em que há mais parcerias do que desentendimentos entre os empreendimentos. No que concerne ao momento em que esses relacionamentos de cooperação se encontram, há indícios de que estejam, em maior ou menor magnitude, em ascensão.

De modo geral, os empreendimentos veteranos, assim como aqueles com médio tempo de atuação e os recém-entrantes sinalizaram para práticas cooperativas crescentes. Para quase metade dos respondentes (61\%), é possível se perceber um aumento da cooperação entre os food trucks da cidade. É válido salientar que entre esses respondentes estavam quase todos os empreendimentos categorizados como veteranos. Por outro lado, pouco mais de um terço dos respondentes (32\%) discordaram ao afirmar que não percebem aumento em tais práticas de cooperação. O percentual residual $(6 \%)$ corresponde aqueles que não souberam opinar sobre esse ponto. Esperava-se uma maior abstenção entre os empreendimentos com menor tempo de atuação no ramo, o que não foi verificado.

Hoffmann et al. (2016) constataram que organizações com tempo de atuação próximo revelaram semelhanças entre si quanto ao arranjo dos seus recursos organizacionais. Particularmente quanto aos três food trucks com maiores tempo de atuação, percebeu-se que a percepção deles acerca dos relacionamentos de cooperação dentro do segmento em que atuam, bem como o networking estabelecido por eles, foram bastante similares. 


\section{RELACIONAMENTOS DE COOPERAÇÃO ENTRE EMPRESAS DE MICRO E PEQUENO PORTE: UM ESTUDO DOS FOOD TRUCKS DO DISTRITO FEDERAL}

Segundo Olave e Amato Neto (2001), pequenos empreendimentos normalmente estão inseridos em contextos que as impelem a diferentes formas de se fazer negócios ao longo do tempo, haja vista a limitação de recursos disponíveis. Considerando o recente tempo de atuação dos food trucks abordados na região, é possível se vislumbrar que a existência de cooperação entre eles possa estar relacionada ao desconhecimento do mercado. Dessa forma, uma alternativa de se conhecer esse segmento econômico seria formando parcerias com antigos atuantes nele (BARNEY; HESTERLY, 2007).

O cenário competitivo inicial marcado pelos empreendimentos com tempo de atuação mais antigo constituise da presença de 5 food trucks: 3 pertencente ao ramo de refeições, 1 do ramo de bebidas e outro do ramo de gelados. A complementaridade dos itens ofertados inicialmente pelos empreendimentos sugere que as parcerias iniciais possam ter se estabelecido por essa razão. Nesse ínterim, segundo maioria expressiva dos respondentes $(90 \%)$, o relacionamento com empreendimentos que ofertam produtos distintos ou complementares é apontado como fácil.

Ao longo do tempo, novos empreendimentos do ramo de refeições começaram a integrar esse grupo inicial: 19 novos food trucks ofertantes de refeições. Por outro lado, não houve expansão significativa entre aqueles do ramo de bebidas e gelados, respectivamente 1 e 3 novos empreendimentos. Percebe-se, dessa forma, que as relações de cooperação mudaram de natureza: não mais entre food trucks ofertantes de itens distintos e/ou complementares, mas sim entre similares.

Analisando os empreendimentos conforme o tempo de atuação na cidade, mesmo diante dessa mudança de cenário competitivo, prevalece a sensação de aumento dos relacionamentos cooperativos, embora a percepção de facilidade em se relacionar com empreendimentos similares não seja tão expressiva (61\%) quanto aquele registrado para os distintos ou complementares (90\%). Entre todos os tipos de incentivos para ingressar em ações de cooperação, Barney e Hesterly (2007) afirmam que a complementaridade de recursos é a mais central.

A Teoria do Custo de Transação ensina que num mundo ideal sem a existência de oportunismo, os relacionamentos econômicos entre firmas poderiam ser baseados na promessa, sem necessidade de contratos (BARNEY, 1991). Ao constatar a presença de confiança mútua entre os food trucks, conforme apontado por $87 \%$ dos respondentes, assim como a existência de comportamento oportunista entre eles, infere-se que, no contexto estudado, embora algumas ações possam ser consideradas como oportunistas, não foram suficientes para minar a confiança e a cooperação entre os empreendimentos.

Esta percepção poderia ser explicada pelo tempo de existência dessas microempresas. Uma vez que ao se perceberem em um mercado novo, sem vínculos existentes, e buscando seu espaço no mercado, eles possam ter visualizado a importância de trabalharem juntos, cooperando entre si para alcançarem seus objetivos, sendo esta ideia coerente com a justificativa para a cooperação apresentada por Casarotto e Pires (2001).

O entendimento que existe a confiança entre os food trucks é corroborado pela minoritária expressividade de respondentes que afirmaram que existem comportamentos oportunistas e individualistas (29\%). Não foi possível, no entanto, elencar quais as ações eram notadas como oportunistas/individualistas. Acerca da existência de contratos formais para a formação de parcerias entre as empresas, houve um equilíbrio nas respostas: $52 \%$ sinalizaram que possuíam contratos firmados com outros food trucks, ao passo que $32 \%$ discordaram em possuir contratos. Pode-se dizer que as relações existentes são realizadas com base em contratos, mas também baseadas em confiança ou cooperação de base não contratual, conforme Hoffmann et al. (2007).

Resumidamente, conforme ilustrado no Gráfico 1, pode-se verificar que os relacionamentos cooperativos entre os Food Trucks participantes da pesquisa são reconhecidos pela maioria como existentes, informais, marcados pela confiança e vistos como em ascensão, independentemente do tempo de existência do negócio. Soma-se a este entendimento que é tido como mais fácil o relacionamento entre empreendimentos 
que ofertam produtos distintos ou complementares, do que com aqueles que ofertam produtos similares. Todavia, mesmo entre os concorrentes diretos, a cooperação é vista como existente pela maioria, ainda que menos expressiva.

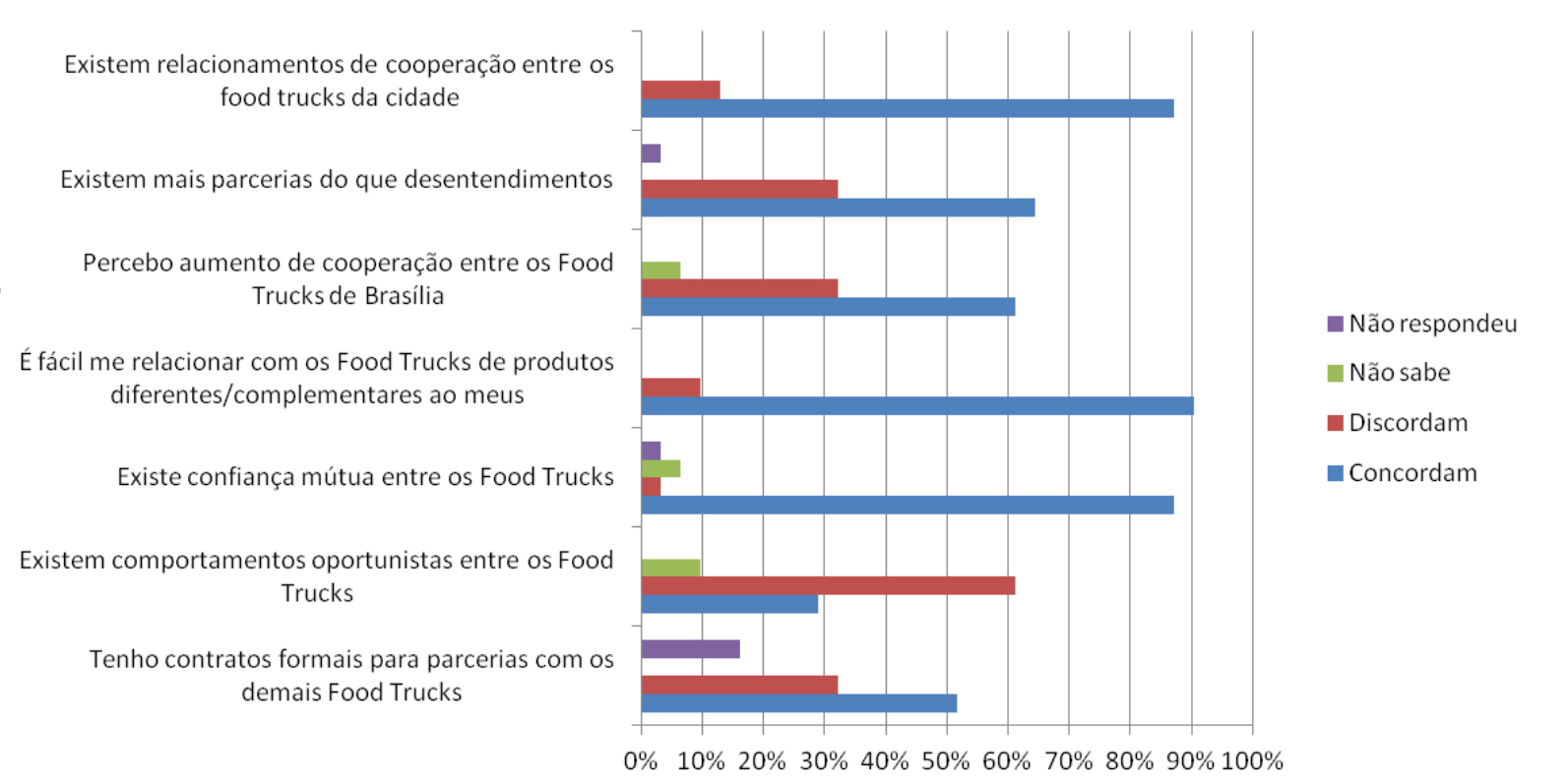

Gráfico 1 - Frequência dos relacionamentos de cooperação entre os Food Trucks do DF Fonte: pesquisa de campo

\section{As ações de cooperação e os benefícios observados pelos Food Trucks}

Na seção anterior, evidenciou-se que o cenário competitivo entre o comércio itinerante dos food trucks investigados é caracterizado, predominantemente, por relacionamentos de cooperação. Quanto às ações de cooperação estabelecidas entre os food trucks, percebeu-se que, de modo geral, os gerentes consideram importante ter parcerias, concordando com a existência delas. Entretanto, essas parcerias aproximam-se mais de ações cooperativas simplistas.

Os eventos são momentos oportunos para que os empreendimentos que atuam no segmento itinerante dos food trucks (WILLIAMS, 2013). Analisou-se a frequência de cooperação em práticas ou ações prévias, simultâneas e posteriores aos eventos. Entre aquelas que ocorrem previamente a eventos, foram investigadas a iniciativa na organização e a indicação de outros food trucks para participar dos eventos. Simultaneamente ao evento, analisou-se a indicação de outros food trucks para os consumidores. Quanto às práticas ou ações posteriores aos eventos, investigou-se a cooperação para realizar investimentos em melhorias de infraestrutura nos local onde eles ocorrem. Isso revela que os relacionamentos tendem a ser demonstrados em distintas tarefas e momentos, ainda que os food trucks não se encontrem sempre aglomerados, em razão de sua natureza móvel.

Para todos os aspectos investigados concernentes aos eventos, houve maioria de concordância sinalizando a existência de cooperação entre os food trucks. A iniciativa na organização e indicação de outros empreendimentos para participar dos eventos alcançaram, respectivamente, $71 \%$ e $100 \%$ de concordância entre os respondentes. Aindicação no momento do evento de outros food trucks aos consumidores alcançou $97 \%$ de concordância dos respondentes, sendo a ação cooperativa mais expressiva. Em relação aos investimentos em melhorias de infraestrutura também foi registrado o percentual de $87 \%$ de concordância à existência de cooperação nesse sentido. 


\section{RELACIONAMENTOS DE COOPERAÇÃO ENTRE EMPRESAS DE MICRO E PEQUENO PORTE: UM ESTUDO DOS FOOD TRUCKS DO DISTRITO FEDERAL}

No conjunto dos dados, percebe-se um panorama em que existe menor frequência da prática de cooperação para a organização de eventos em relação à ação de indicação de outros food trucks para participar deles. Por outro lado, a prática de investimento em infraestrutura nos locais dos eventos apresentou frequência também elevada. Esses dados deixam entrever que embora possa haver receio para se organizar os eventos, uma vez que são organizados, os food trucks indicam outros para dar volume ou fazer acontecer 0 evento. E mesmo no decorrer do evento, há indicação mútua entre eles para os consumidores.

As evidências mostram que como o local do evento é de uso coletivo a todos os empreendimentos instalados, e considerando que a imagem do evento pode refletir na imagem dos participantes, haveria uma preocupação maior em torno dos investimentos em infraestrutura. Nesse ponto, referencia-se Souza e Lopes (2017), os quais recomendam a esse tipo de empreendimento a melhoria do conforto dos usuários por meio de coberturas móveis e implementação de algum tipo de sonorização para agradar os consumidores. Dessa forma, o elevado grau de concordância de cooperação para esse requisito pode ser em função de que cada parte contribui à infraestrutura do todo: i) quando investe naquela adjacente ao seu food truck (SOUZA; LOPES, 2017) e/ou ii) quando investe na infraestrutura de uso coletivo, como estacionamento e segurança (LUDWIG; NETO, 2017).

Entre outros possíveis, um momento oportuno para discutir tais pontos seria em reuniões. Quando questionados se realizam reuniões para discutir possíveis melhorias no mercado de food truck, $77 \%$ dos respondentes sinalizaram que sim. A investigação buscou identificar também a existência de ações de cooperação quanto ao treinamento ou realização de palestras aos funcionários e proprietários; realização de compras de insumos; divulgação ou marketing conjunto; contratações de consultorias para resolução de problemas; compartilhamento de informações de mercado e realização de reuniões.

O compartilhamento de informações de mercado foi também um item com bastante concordância $(97 \%)$ de existência de cooperação entre os food trucks. A importância do compartilhamento de informações reside na propensão de maior ganho às empresas envolvidas (BALESTRIN; VARGAS; FAYARD, 2005). Destarte, se por um lado o compartilhamento de informação acerca dos processos produtivos, fornecedores, insumos, tecnologias e mercados pode trazer benefícios a empresas que cooperam entre si (BALESTRIN; VARGAS; FAYARD, 2005), por outro lado, há informações insuscetíveis de compartilhamento por empresas envolvidas em cooperação, a exemplo daquelas particulares envolvendo faturamento mensal e despesas (TÁLAMO; CARVALHO, 2004).

Entre outros fatores, é de se pressupor que a característica de comércio itinerante dos food trucks, demande substancial esforço quanto às ações de divulgação, não apenas dos empreendimentos em si, mas também dos eventos em que ocorrerá a participação deles. Entre os food trucks abordados, a concordância de que há cooperação na divulgação em conjunto entre os empreendimentos foi elevada (97\%). As redes sociais, a exemplo do Facebook e Twitter (WILLIAMS, 2013), funcionam como principal meio de divulgação entre os food trucks abordados. Segundo Perini e Guivant (2017), além da divulgação nas redes sociais, os proprietários de food trucks fazem uso das ferramentas presentes nelas para estabelecer contato direto com seus clientes e outras relacionadas a mecanismos de avaliação online.

Embora a cooperação entre empresas de mesmo porte, atuantes no mesmo segmento de mercado e com oferta de produtos congêneres possa ser um facilitador à realização conjunta de compras e publicidade, assim como possibilitar o desenvolvimento de tecnologias e inovações (TÁLAMO; CARVALHO, 2004), as frequências registradas de concordância para alguns desses itens foram menos expressivas: realização conjunta de treinamentos para os funcionários $(48 \%)$, contratação conjunta de consultorias para resolução de problemas comuns (35\%) e compra coletiva de insumos necessários às atividades dos food trucks (23\%). Percebe-se, dessa forma, que a cooperação que envolve esforços mais complexos e menos suscetíveis ao efeito carona são menos corriqueiras, aproximando-se mais de ações de cooperação isoladas do que práticas de cooperação enraizadas. O Gráfico 2 ilustra a frequência das ações de cooperação entre os food 
trucks abordados.

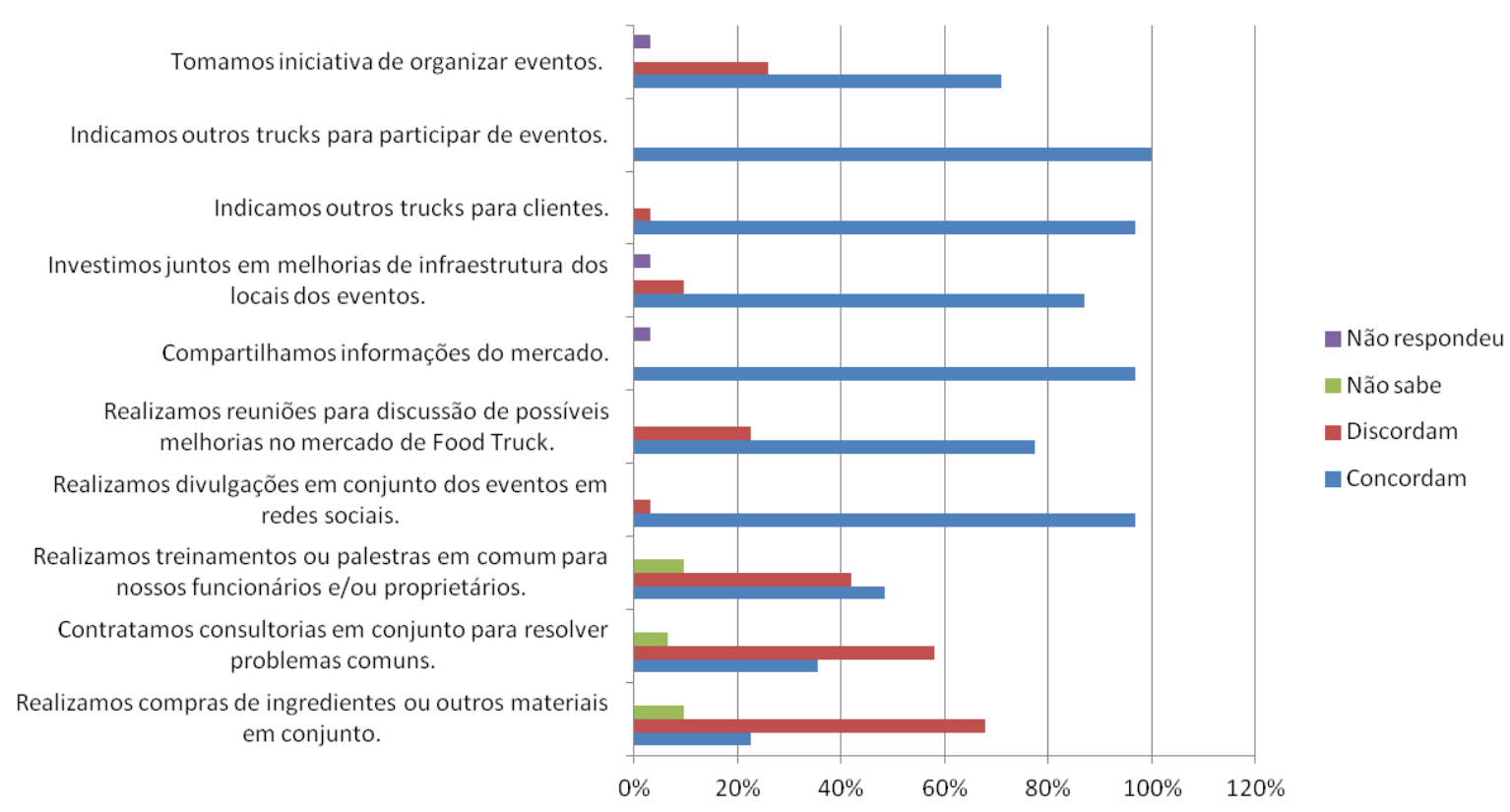

Gráfico 2: Frequência das ações de cooperação entre os Food Trucks do DF Fonte: pesquisa de campo.

Entre os benefícios percebidos como advindos da cooperação entre os food trucks abordados, com os mais altos percentuais de concordância dos respondentes (acima de 75\%), destacam-se: ampliação da força política desses empreendimentos na cidade (96\%); aumento de conhecimentos para o negócio (90\%); aumento da divulgação e aumento da clientela ( $86 \%$ cada), e desempenho financeiro ( $80 \%)$; e inovações do processo ou produto comercializado $(75 \%)$.

Revelou-se, portanto, que entre as 7 variáveis observadas, 6 obtiveram concordância da maioria, demonstrando um expressivo entendimento de que a cooperação tem apresentado vantagens, ainda que 0 setor e as empresas sejam recentes e as ações também. O benefício que se mostrou com o maior número de concordância se referia à ampliação da força política dos food trucks em Brasília. Daí sugere-se que, além dos proprietários estarem engajados para que o setor se torne representativo para o Governo do Distrito Federal, esse aumento da força política também pode ter sido evidenciada por possíveis fortalecimentos dos relacionamentos de cooperação, além das outras ações já citadas. Afinal, o setor passava pela mobilização coletiva, inclusive com a participação em um grupo de trabalho junto ao governo do DF, para a formulação de regras para o setor.

A única vantagem que foi amplamente discordada, com $70 \%$ de rejeição, afirmava que havia facilidades de acesso à crédito bancário. Esse resultado mostra-se razoável com o nível de organização, inclusive político do setor, visto que eles ainda não se tornaram legalizados na cidade. Apesar deste item negativo, as vantagens sugeridas se mostraram amplamente perceptíveis aos empresários do setor, com altos índices de concordância.

\section{Conclusões}

O presente estudo buscou investigar os relacionamentos de cooperação entre food trucks do Distrito Federal e os benefícios alcançados advindos das ações conjuntas entre eles. Para tanto, buscou-se evidenciar como os food trucks percebem os relacionamentos de cooperação entre eles e de que forma ocorrem.

O enfoque teórico assentou-se na visão baseada em recursos. A cooperação foi entendida como práticas ou ações realizadas conjuntamente por empresas congêneres que competem entre si no mercado (CASAROTTO; PIRES, 2001) indo ao encontro do conceito de cooperação horizontal na tipologia delineada 


\section{RELACIONAMENTOS DE COOPERAÇÃO ENTRE EMPRESAS DE MICRO E PEQUENO PORTE: UM ESTUDO DOS FOOD TRUCKS DO DISTRITO FEDERAL}

por Hoffmann et al. (2007). Por sua vez, os food trucks podem ser considerados empreendimentos itinerantes (WILLIAMS, 2013) e, no caso desse estudo, foram abordados aqueles atuantes no ramo alimentício.

Para o alcance da proposta desse estudo, realizou-se uma pesquisa descritiva com abordagem quantitativa. $O$ instrumento de coleta de dados foi o questionário adaptado de Miranda Júnior (2013) conforme a literatura específica consultada para esse estudo. A amostragem foi do tipo não probabilística por conveniência. Ao todo, chegou ao número de 31 questionários válidos respondidos por proprietários de food trucks atuantes em eventos específicos a esse tipo de comércio. A análise dos dados coletados deu-se por meio de estatística descritiva.

Quanto à caracterização dos food trucks abordados, os resultados evidenciaram um setor de microempresas de atuação recente, sendo as atuações mais remotas estabelecidas há 18 meses (da época da coleta dos dados, ocorrida em dezembro de 2015). Essa aproximação de tempo de atuação leva empresas a tenderem a configurar seus recursos organizacionais de modo semelhante (HOFFMANN et al., 2016). $O$ faturamento predominante foi de $\mathrm{R} \$ 10$ mil por mês e grande maioria dos empreendimentos emprega entre 2 a 4 funcionários. Assim, conforme a metodologia do Sebrae (2013) que mensura o porte das empresas por meio da quantidade de funcionários empregados, todos os food trucks abordados nesse estudo podem ser classificados como microempresas. Quanto aos itens comercializados, embora havendo certa variedade de produtos ofertados, registrou-se predominância de hambúrgueres e sanduíches.

Segundo os respondentes, existe relacionamento de cooperação entre os food trucks abordados, com indícios de ascensão. $\mathrm{O}$ ambiente competitivo revelou-se amistoso, havendo mais parcerias do que desentendimentos. As evidências apontam, entretanto, que há maior facilidade em se relacionar com empreendimentos complementares (vendedor de hambúrguer e vendedor de bebida, por exemplo) do que com aqueles congêneres (vendedores de sanduíche), o que traz um insumo para refinar a compreensão sobre a cooperação horizontal, levando em consideração a natureza da oferta do negócio e como isso pode impactar no balanço cooperação/competição.

Os resultados também sinalizaram que, embora haja a presença de comportamentos oportunistas, paira sobre os relacionamentos entre os food trucks a predominância de confiança mútua ao ponto de esses relacionamentos não serem estabelecidos por contratos. Esses achados deixam entrever duas possíveis conclusões: i) resistência: o oportunismo presenciado por alguns food trucks não parece ter sido suficiente para minar a confiança e a cooperação entre eles ou ii) oportunismo alheio: existência de atores centrais na rede de cooperação, sendo o comportamento oportunista presenciado fora das interconexões com tais atores.

Em relação à cooperação entre os empreendimentos pesquisados, foi possível verificar que as ações de parcerias estão articuladas com os eventos em que participam conjuntamente, ou seja, nos momentos em que decidem estar aglomerados. Assim, estas ações ocorrem antes (no preparo do evento), durante (com as indicações aos clientes) e depois (com iniciativas de melhorias dos espaços que utilizam). Notou-se prevalência daquelas ações mais simples de serem adotadas, como por exemplo, realizar indicações para clientes ou para participação em eventos. Por outro lado, as ações mais complexas, como realizar compras de ingredientes em conjunto e contratar consultorias para resolução de problemas em comum, foram apontadas com menor recorrência.

Os benefícios alcançados pelas ações de cooperação foram amplamente corroborados entre os respondentes, com exceção do acesso ao crédito bancário. Destaca-se a maior força política proveniente da ação conjunta entre os food trucks, elemento que ganha destaque dentro do contexto em que vivem da busca e dos desafios impostos pela regularização da atividade. Não obstante, a cooperação entre eles conduziu ao aumento do conhecimento sobre o negócio e maior divulgação. Ainda que o conjunto de ações bastante recorrente não seja vasto, pode-se perceber que os gestores tendem a perceber resultados 
positivos que podem gerar benefícios econômicos e não econômicos (BALESTRIN; VARGAS, 2004), proporcionando um possível aumento de competitividade do setor (WILLIAMS, 2013).

Em suma, o presente estudo contribui para a literatura de empresas de pequeno porte haja vista 0 pioneirismo em se investigar a cooperação entre empresas que, embora aglomeradas geograficamente, mudam sua localização conforme os eventos que ocorrem na cidade. Dessa forma, a mobilidade inerente aos food trucks desafiam a literatura acerca de aglomeração territorial das empresas e devem ser mais bem explorada em estudos futuros. Ainda, como agenda de pesquisa, sugere-se a abordagem qualitativa do fenômeno da cooperação entre os food trucks, no intuito de constatação de novos ou mais aprofundados dados e informações.

\section{Referências}

ANENBERG, E.; KUNGB, E. Information technology and product variety in the city: The case of food trucks. Journal of Urban Economics, vol. 90, p. 60-78, 2015.

BALESTRIN, A.; VARGAS, L. M. A dimensão estratégica das redes horizontais de PMEs: teorizações e evidências. Revista de Administração Contemporânea - RAC, v. Edição esp, p. 203-227, 2004.

BALESTRIN, A.; VARGAS, L. M.; FAYARD, P. Ampliação Interorganizacional do Conhecimento: 0 caso das redes de cooperação. Revista Eletrônica de Administração, v. 11, n. 1, p. 1-25, 2005.

BALESTRIN, A.; VERSCHOORE, J. R.; PERUCIA, A. A visão relacional da estratégia: evidências empíricas em redes de cooperação empresarial. Revista de Administração e Contabilidade da Unisinos - BASE, v. 11, n. 1, p. 47-58, 2014.

BARNEY, J. Firm resources and sustained competitive advantage. Journal of Management, v. 17, n. 1, p. 99-120, 1991.

CASAROTTO FILHO, N.; PIRES, L. H. Redes de Pequenas e Médias Empresas e Desenvolvimento Local. São Paulo: Atlas, 2001.

CASTRO, M. DE; BULGACOV, S.; HOFFMANN, V. E. Relacionamentos interorganizacionais e resultados: estudo em uma rede de cooperação horizontal da região central do Paraná. Revista de Administração Contemporânea, v. 15, n. 1, p. 25-46, 2011.

EISENHARDT, K.; SCHOONHOVEN, C. B. Resource-based view of strategic alliance formation: strategic and social effects in entrepreneurial firms. Organization Science, v. 7, n. 2, p. 136-150, 1996.

GEROLAMO, M. C. et al. Clusters e redes de cooperação de pequenas e médias empresas: observatório europeu, caso alemão e constribuições ao caso brasileiro. Revista Gestão \& Produção, v. 15, n. 2, p. 351$365,2008$.

HEINE, K.; RINDFLEISCH, H. Organizational decline: a synthesis of insights from organizational ecology, path dependence and the. Journal of Organizational Change Management, v. 26, n. 1, p. 8-28, 2013.

HOFFMANN, V. E., LEONELO, A. M., DIAS, C. N.; MATIAS, I. Recursos estratégicos para vantagem competitiva sustentávle em Food Trucks. Revista Alcance, v. 23, n. 3, 2016.

HOFFMANN, V. E.; MOLINA-MORALES, X.; MARTÍNEZ-FERNÁNDEZ, T. Redes de Empresas: proposta de uma tipologia para classificação aplixada na indústria de cerâmica de revestimento. Revista de Administração Contemporânea - RAC, v. 1a Edição, n. 1, p. 103-127, 2007.

LUDWIG, E. L.; NETO, E. H. Segurança Alimentar em Comida de Rua: um estudo sobre a percepção e motivação do consumo no Mamute Food Truck em Foz do Iguaçu - PR. 11o Fórum Internacional de Turismo do Iguassu. Anais...Paraná: 2017

MAGALHÃES, J. M. DE; DAUDT, C. G.; PHONLOR, P. R. Vantagens Proporcionadas às Pequenas e Médias 
Empresas por meio da União em Redes de Cooperação no Contexto do Venture Capital. Revista de Administração Contemporânea - RAC, v. 13, n. 4, p. 583-603, 2009.

MARQUES, C. et al. Estudo da viabilidade para implantação de um food truck de comidas saudáveis com o apoio de um plano de negócio. XI Jornada Científica - Faculdades Integradas de Bauru - FIB. Anais...2016 Miranda Júnior, N. S. Dificuldades para estabelecer ações de cooperação: estudo dos hotéis em Brasília. Monografia de graduação, Universidade de Brasília, Distrito Federal, DF, Brasil, 2013.

OLAVE, M. E. L.; NETO, J. A. Redes de cooperação produtiva: uma estratégia de competitividade e sobrevivência para pequenas e médias empresas. Gestão \& Produção, v. 8, n. 3, p. 289-303, 2001.

PERINI, K. P.; GUIVANT, J. S. Comer em food trucks à luz da Teoria das Práticas. Estudos, Sociedade e Agricultura, v. 25, n. 2, p. 305-326, 2017.

SEBRAE. Food Truck: uma nova tendência Uma nova tendência O modelo Food Truck, 2017. Disponível em: <https://www.sebrae.com.br/sites/PortalSebrae/artigos/food-truck-uma-nova-tendencia>.

SCHIFELING, T.; DEMETRY, D. The Rise of the Authenticity Economy: A Study of the Transformation and Spread of Food Trucks. Academy of Manament Proceedings, January 2014.

SILVA, G. D. L.; LIMA, L. F.; LOURENÇO, N. S. Food truck na cidade de São Paulo e a influência do perfil do consumidor em sua longevidade: aspectos socioculturais. Revista FATEC Zona Sul, v. 2, n. 1, p. 1-23, 2015.

SOUZA, B. R. DE; LOPES, E. L. Uma análise sobre os atributos de negócios dos food trucks que mais influenciam a intenção de recomendação e reuso desse modelo de negócio. Revista da Micro e Pequena Empresa, v. 11, n. 1, p. 20-33, 2017.

TÁLAMO, J. R.; CARVALHO, M. M. DE. Seleção dos objetivos fundamentais de uma rede de cooperação empresarial. Gestão \& Produção, v. 11, n. 2, p. 239-250, 2004.

VERSCHOORE; BALESTRIN, A. Fatores relevantes para o estabelecimento de redes de cooperaçăo entre empresas do Rio Grande do Sul. Revista de Administração Contemporânea - RAC, v. 12, n. 4, p. $1043-$ 1069, 2008.

VERSCHOORE, J.; BALESTRIN, A. A associação em redes de cooperação influencia os resultados de pequenas e médias empresas? Ciências Sociais Unisinos, 46(1), p. 105-115, 2010. https://doi.org/10.4013/csu.2010.46.1.11

WILLIAMS, C. A Hungry Industry on Rolling Regulations : A Look at Food Truck Regulations in Cities Across the United States. Maine Law Review, v. 65, n. 2, p. 706-717, 2013. 